\title{
Fracture Morphology of Carbon Fiber Reinforced Plastic Composite Laminates
}

\author{
Vinod Srinivasa ${ }^{\mathrm{a}, \mathrm{b}, \%}$, Vinay Shivakumar $^{\mathrm{a}, \mathrm{c}}$, Vinay Nayaka ${ }^{\mathrm{a}}$, Sunil Jagadeeshaiaih ${ }^{\mathrm{a}}$, \\ Murali Seethram ${ }^{\mathrm{a}, \mathrm{d}}$, Raghavendra Shenoy ${ }^{\mathrm{a}, \mathrm{b}}$, Abdelhakim Nafidi ${ }^{\mathrm{e}}$ \\ ${ }^{a}$ Mechanical Engineering Department, RV College of Engineering, Bangalore, 560 059, India \\ ${ }^{\mathrm{b}}$ Presently at Larsen \& Toubro Ltd., Vadodara, 390 019, Gujarat, India \\ 'Toyota Kirloskar Motor Pvt. Ltd., Bangalore, 562 109, Karnataka, India \\ ${ }^{\mathrm{d}}$ Auden Technology and Management Academy, Bangalore, 560 017, India \\ ${ }^{\mathrm{e}}$ Group of Condensed Matter Physics, University of Ibn Zohr, 80000 Agadir, Morocco
}

Received: June 3, 2010; Revised: July 12, 2010

\begin{abstract}
Carbon fiber reinforced plastic (CFRP) composites have been extensively used in fabrication of primary structures for aerospace, automobile and other engineering applications. With continuous and widespread use of these composites in several advanced technology, the frequency of failures is likely to increase. Therefore, to establish the reasons for failures, the fracture modes should be understood thoroughly and unambiguously. In this paper, CFRP composite have been tested in tension, compression and flexural loadings; and microscopic study with the aid of Scanning Electron Microscope (SEM) has been performed on failed (fractured) composite surfaces to identify the principle features of failure. Efforts have been made in correlating the fracture surface characteristics to the failure mode. The micro-mechanics analysis of failure serves as a useful guide in selecting constituent materials and designing composites from the failure behavior point of view. Also, the local failure initiation results obtained here has been reliably extended to global failure prediction.
\end{abstract}

Keywords: CFRP, tension-compression-flexure loading, fractography, failure modes

\section{Introduction}

Composite materials derived from epoxy resin and carbon fibers are being extensively employed in aircraft industries because of their strength, high modulus and light weight ${ }^{1-4}$. Carbon fiber reinforced plastic (CFRP) offer their greatest advantage over isotropic materials when their fiber axes are aligned in the direction of the principal stress $^{5}$. CFRP and hybrid composites out perform their aluminium counterparts in terms of low weight for a required stiffness or strength. Also, the weight reduction with hybrid composites is not as great as for CFRP composites. Hence, engineers in many fields have turned to carbon fiber reinforced polymers to design stiff light weight structures ${ }^{6,7}$.

The efficient design of structures requires a detailed understanding of the fracture behavior of the material and the modes of failure of the component, knowledge which is also necessary for the airworthiness flight clearance and the post-mortem examination of failed components ${ }^{1}$. The fractography of different CFRP unidirectional (UD) or multidirectional (MD) composite materials have been the subject of several studies by many investigators ${ }^{1,8-12}$ over the last four decades. Some specific fractographic characteristics were identified in these investigations. But the results from composite fractography is not as mature as the fractographic analysis of surface morphology of metal components ${ }^{13-15}$, but has a tremendous scope to bring composites fractography to the level of maturity akin to that of isotropic materials ${ }^{16-17}$.

To model the crack propagation processes, particularly those pertinent to progressive damage growth, it is important to understand the physical mechanisms of composite fracture, which is accomplished by fractography, wherein the examination of fracture surfaces give valuable information about damage and the failure of the components. This approach gives an understanding of the fundamental failure processes and mechanisms associated with modes of failure. And further helps in interpretation of more complex components whose cause of failure is unknown ${ }^{17}$. Furthermore, in many materials it can provide valuable information about the local service environment or stress state responsible for crack initiation ${ }^{14}$.

It was also established ${ }^{1,5}$ that in a multi-directionally layered material each ply has very much the same fractographic features as a UD material for the same direction of fibers. Accordingly, the fractography of UD composites can serve as a basis for the fractography of multidirectional composites. Hence, this paper gives the fractographic investigations of failures in CFRP by considering the fracture of CFRP under tension, compression and flexure modes of failure to provide the fractographic understanding and to establish the expertise necessary to analyze successfully the fracture modes, failure sequence and initial cause of CFRP structural breakdown.

\section{Experimental}

\subsection{Materials}

The reinforced epoxy composites were manufactured by stacking the pre-impregnated (prepegs) layers into an open mould and cured at $180{ }^{\circ} \mathrm{C}$ for 4 hours. The prepegs were prepared in the laboratory by impregnating the carbon fiber in the form of sheet, with the epoxy system. For $2 \mathrm{~mm}$ thick specimens, the prepared prepegs consisted of 16 layers of impregnated carbon fiber. The Unidirectional (UD) CFRP prepeg (containing about $65 \%$ by volume of carbon fibers) were used for tensile, compression and flexural studies. 


\subsection{Mechanical testing}

All tests have been carried out on a $100 \mathrm{kN}$ INSTRON Universal Testing Machine (Model: 6025) and the machine cross head was programmed to apply the load at constant strain rate of $0.01 / \mathrm{s}$ through the entire duration of the test. In order to produce a known mode of failure, standard test specimens as per ASTM standards (Table 1) were loaded in axial tension, compression and long beam flexure. All the tests were carried out under ambient conditions. At least five samples were tested for each mode of loading. Figure 1 shows the schematic representation of specimen configuration for tensile, compression and flexural loadings respectively.

Table 1. Test specimen dimensions.

\begin{tabular}{lcc}
\hline \multicolumn{1}{c}{ Loading } & ASTM Standard & Dimensions $(\mathrm{mm})$ \\
\hline Tension & D 3039 & $250 \times 12.5 \times 2$ \\
Compression & D 3410 & $100 \times 10 \times 2$ \\
Flexure & D 790 & $100 \times 10 \times 2$ \\
\hline
\end{tabular}

\subsection{Microscopic examination}

\subsubsection{Material characterization in optical microscope}

The micro-structural evolution for the fractured CFRP composites was studied by Neophot Optical Microscope. The small chips of the samples (Figure 2a) were mounted in the resin to get stubs for grinding and polishing. The mounted samples are initially ground by Silicon Carbide (SiC) of grit size 240, 320, 400 and $600 \mu \mathrm{m}$, followed by alcoholic cleaning after each $\mathrm{SiC}$ grinding. These were then polished with a diamond paste up to $1 \mu \mathrm{m}$. They were finally polished by 0.3 and $0.05 \mu \mathrm{m}$ Alumina powder in a rotating polisher. After the sample is fine polished, it is dried to obtain scratch free microstructure under Optical Microscope.

\subsubsection{Fractographic characterization in scanning electron microscope}

The fractured surface is gold sputtered by evaporation, with Current of $10 \mathrm{~mA}$ and Voltage of $1 \mathrm{kV}$ for a period of 5-8 minutes. The sputtered thickness is $600-800 \mathrm{~A}^{\circ}$. Scanning Electron Microscope (SEM: JSM-5200, JEOL) has been used for the fractographic characterization.

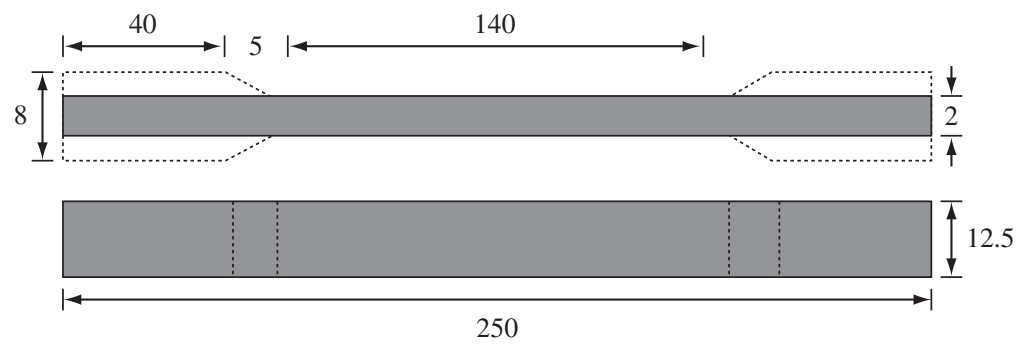

(a)

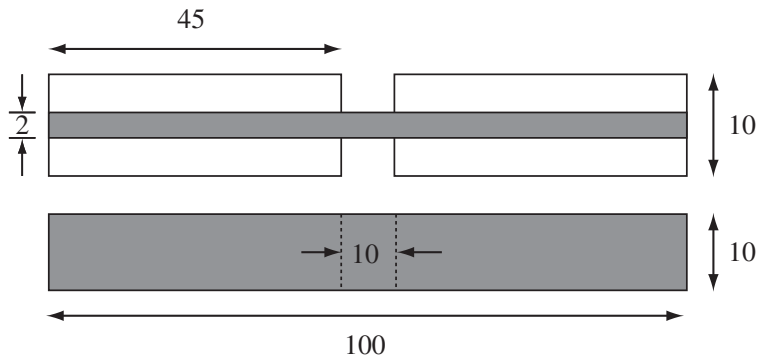

(b)

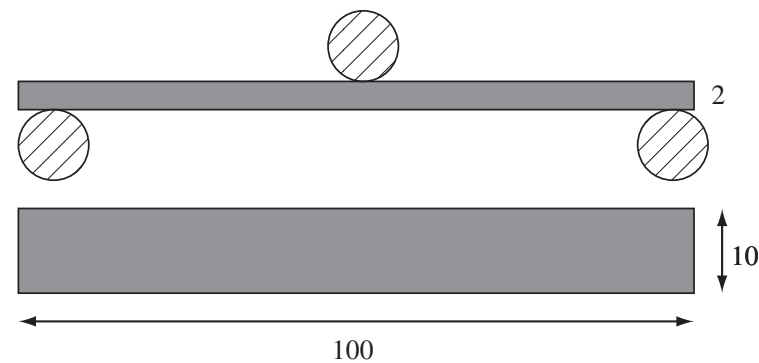

(c)

Figure 1. Schematic representation of specimen configuration used for: a) tensile; b) compression; and c) flexure testing. (All dimensions are in mm)

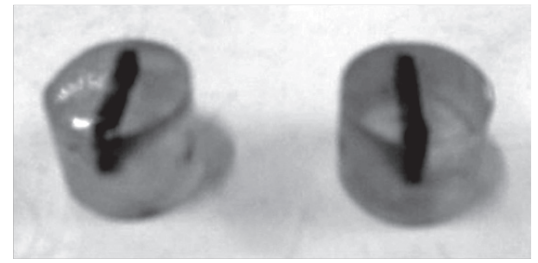

(a)

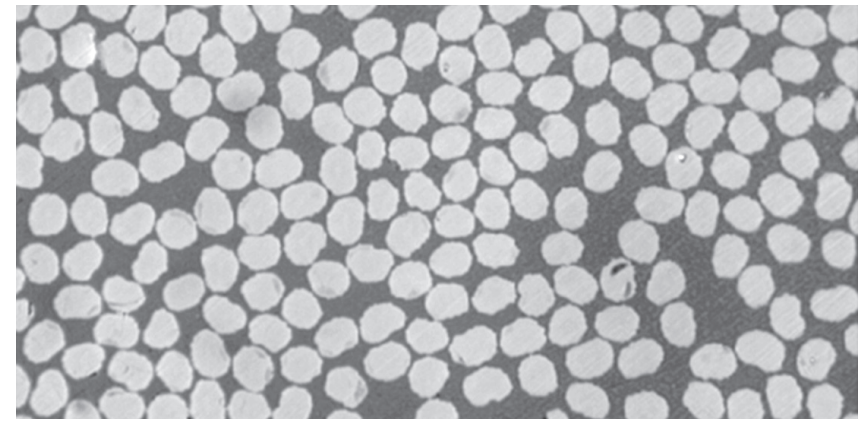

(b)

Figure 2. a) Composite in Epoxy (Stubs); and b) Optical micrograph showing cross sectional uniform distribution of carbon fibers in the epoxy matrix. 


\section{Results and Discussions}

\subsection{Micrographs}

Fairly good (uniform) distribution of carbon fibers in the epoxy matrix seen under Optical Microscope is presented in Figure $2 b$. The CFRP samples were tested for its longitudinal and cross sectional morphology using SEM. Figure 3a shows the SEM micrographs of the cross sectional uniform distribution of carbon fibers in the epoxy matrix and Figure $3 \mathrm{~b}$ shows longitudinal distribution of carbon fibers in the epoxy matrix, indicating the perfect manufacturing process for the specimen under test.

\subsection{Morphology of composites}

\subsubsection{Fractographic characteristics of UD axial tension tested CFRP composite}

An axial tension failed composite test samples led to the fracture in the transverse direction and associated with extensive longitudinal splitting of the composite. The fracture surface of tension-failed sample is shown in Figure 4, wherein three clearly distinguishing regions: crack origin, propagation and final fracture can be identified.

Figure 5a shows magnified crack origin, where a set of fiber bundles was found to be broken. This acted as stress concentrator for initiation and propagation of tensile failure. The entire fracture surface revealed fiber pull-out from the matrix (Figure 5b), which is typical of a non-brittle composite ${ }^{18}$. Also, it's the $90^{\circ}$ cracks that dictate the $0^{\circ}$ ply composite, even though the stress at which the laminate fails is primarily determined by axial plies ${ }^{1,19}$. At higher magnification of about 5000X, microscopic radial marks can be observed on the fractured fibers and are typical characteristic of tensile failure of composite ${ }^{17,20}$ (Figure 5c). Carbon fiber in the composite is magnified at 10,000 times in Figure 5d shows the origin ' $O$ ' and the radiating lines resulting from the axially diverging crack propagation (dotted arrow lines) on fiber fracture surface. In Figure 5e, local crack propagation direction is shown by the arrows.

Crack propagation direction is drawn using the concept of Directly Attributable Fiber Failure (DAFF) method ${ }^{1,18}$. Its' a technique by which the crack front mapping and crack propagation direction is drawn on fractured fibers as shown in Figure $5 \mathrm{f}$. The sequence of fiber failures continued as follows; $a \rightarrow b, b \rightarrow d, d \rightarrow g, g \rightarrow l ; a \rightarrow c$, $\mathrm{c} \rightarrow \mathrm{f}, \mathrm{f} \rightarrow \mathrm{k}, \mathrm{k} \rightarrow \mathrm{r}, \mathrm{r} \rightarrow \mathrm{u}, \mathrm{u} \rightarrow \mathrm{w} ; \mathrm{c} \rightarrow \mathrm{e}, \mathrm{e} \rightarrow \mathrm{h}, \mathrm{h} \rightarrow \mathrm{m} ; \mathrm{e} \rightarrow \mathrm{j}, \mathrm{j} \rightarrow \mathrm{q} ; \mathrm{e} \rightarrow \mathrm{i}$, $\mathrm{i} \rightarrow \mathrm{n}, \mathrm{n} \rightarrow \mathrm{s} ; \mathrm{i} \rightarrow \mathrm{p}, \mathrm{p} \rightarrow \mathrm{t}, \mathrm{t} \rightarrow \mathrm{v}$. The sequence implies that the failure of fibre ' $b, d, g$ ' is a direct consequence of the failure of fibre ' $a$ ' and such failures will be referred to as DAFF. By tracking the paths of DAFF, the fracture of the composite may be accurately charted as it progresses from fibre to fibre as depicted in Figure 6.

This method is repeated at several regions on UD failed samples and recorded fracture features to establish the crack propagation directions. From the concept of DAFF it is possible to trace the crack path and propagation direction on the fracture surface. To assess the fracture path and Crack Propagation Direction (CPD) path on the CFRP failed surface, several micrographs were taken at different regions on fracture surface. Based on the radial features on the fracture fiber ends, a typical Resultant Crack Propagation Direction (RCPD) is drawn on each region. By summing up all these results, overall CPD is drawn to establish crack origin, crack propagation region and final failure region (Figure 6). However, at a few regions, the crack propagation direction through the fibers was different from general crack propagation direction. This may be due to the local fracture in these regions prior to the arrival of the main crack front. Figure 6 shows the map of overall crack propagation direction in tension failed CFRP laminate. White arrows indicate the local crack

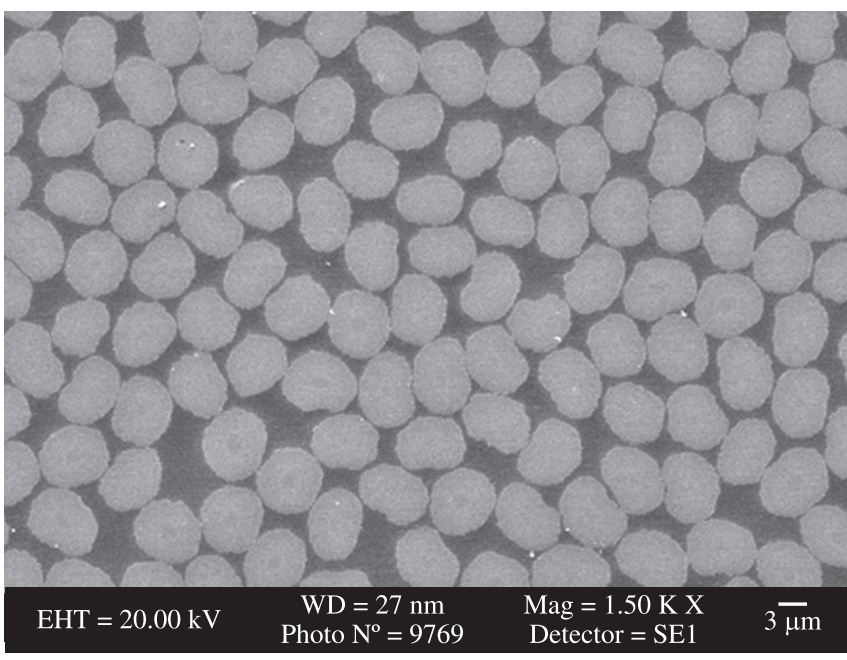

(a)

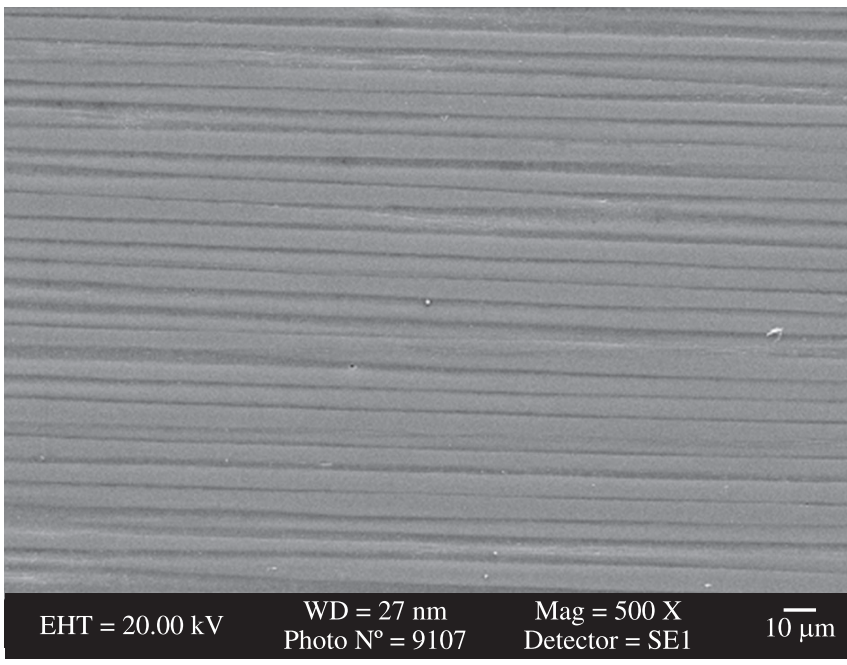

(b)

Figure 3. SEM micrograph showing: a) longitudinal and b) cross sectional uniform distribution of carbon fibers in epoxy matrix.

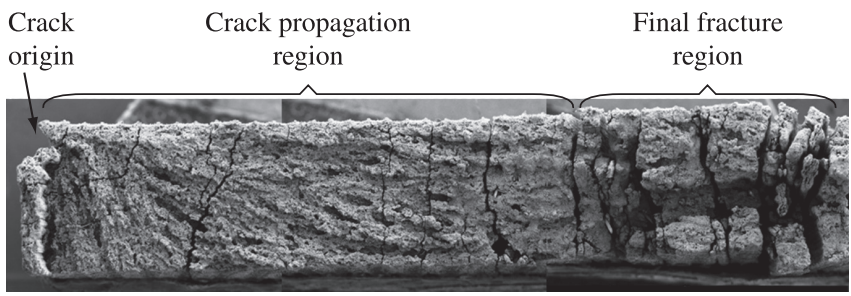

Figure 4. SEM fractograph of the tensile tested specimen. Three regions clearly distinguishing crack origin, propagation and final fracture.

propagation direction and the dotted arrow indicate overall crack propagation direction.

At high magnification, fiber radials indicate the local crack propagation direction (Figure 5e). But at low magnification, Chevron lines (formed because of the propagation of cracks at $90^{\circ}$ into the adjacent $0^{\circ}$ plies) can be clearly seen in Figure 4 . The crack origin was identified by tracing back these lines and found to be at the edge of the sample (shown by arrow in Figure 5a and Figure 6), i.e., the overall crack propagation direction in most of the regions (Figure 6) 


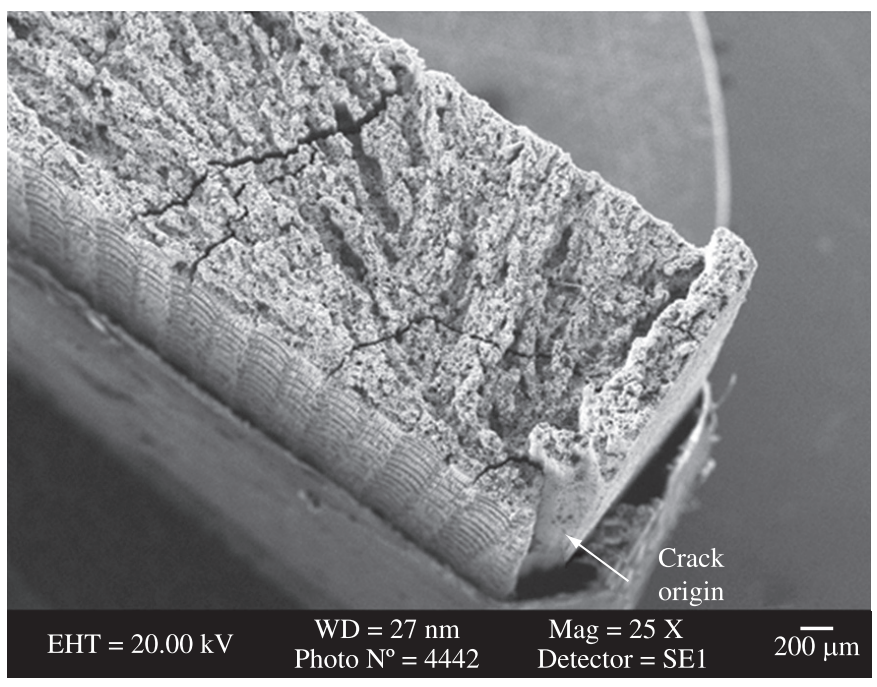

(a)

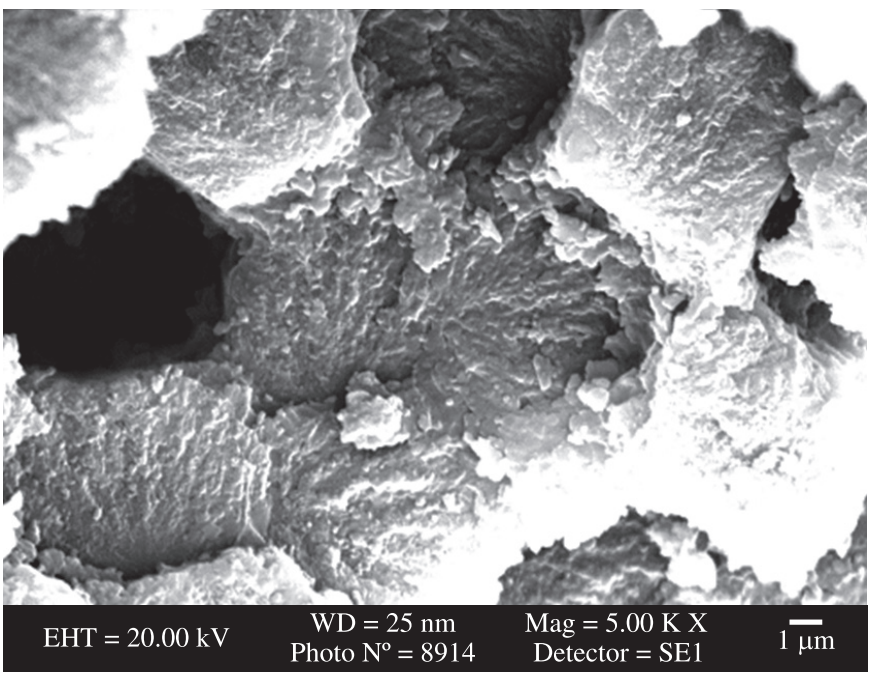

(c)

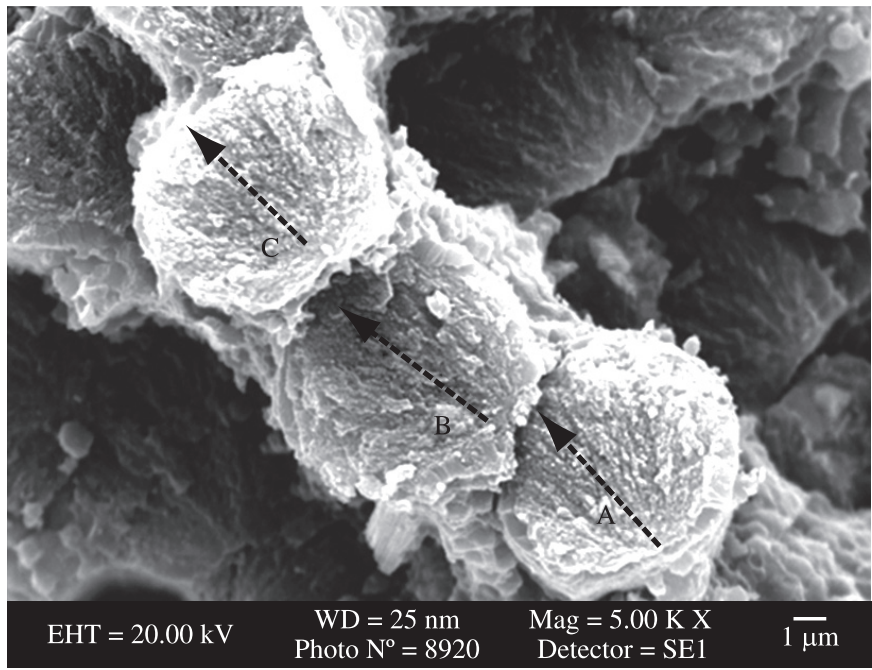

(e)

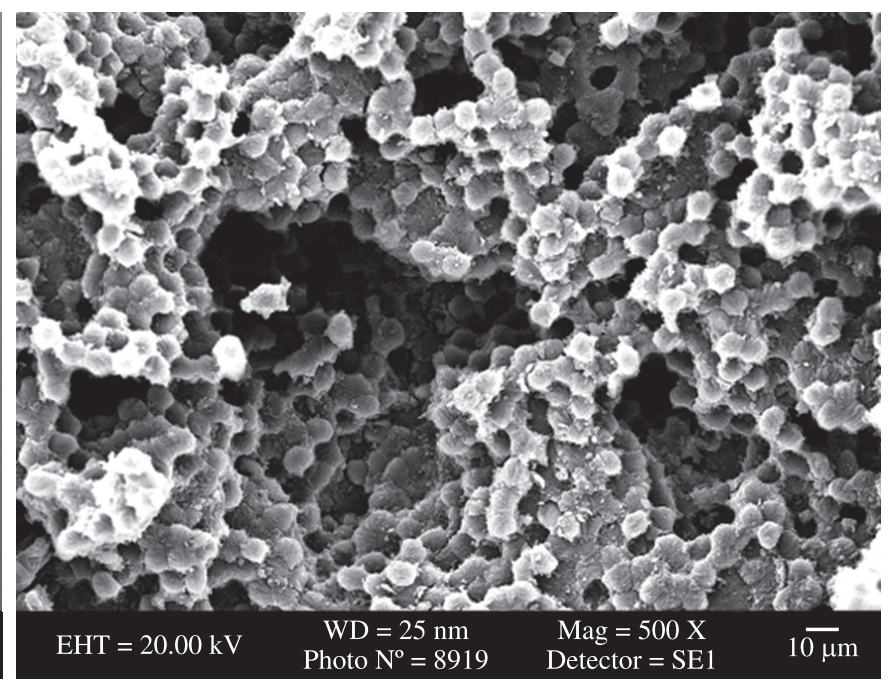

(b)

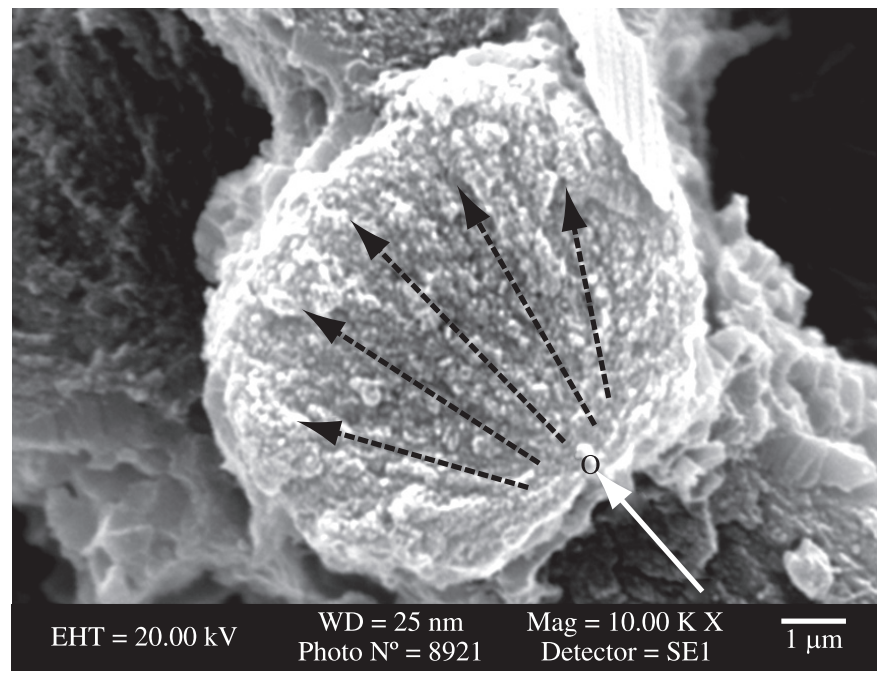

(d)

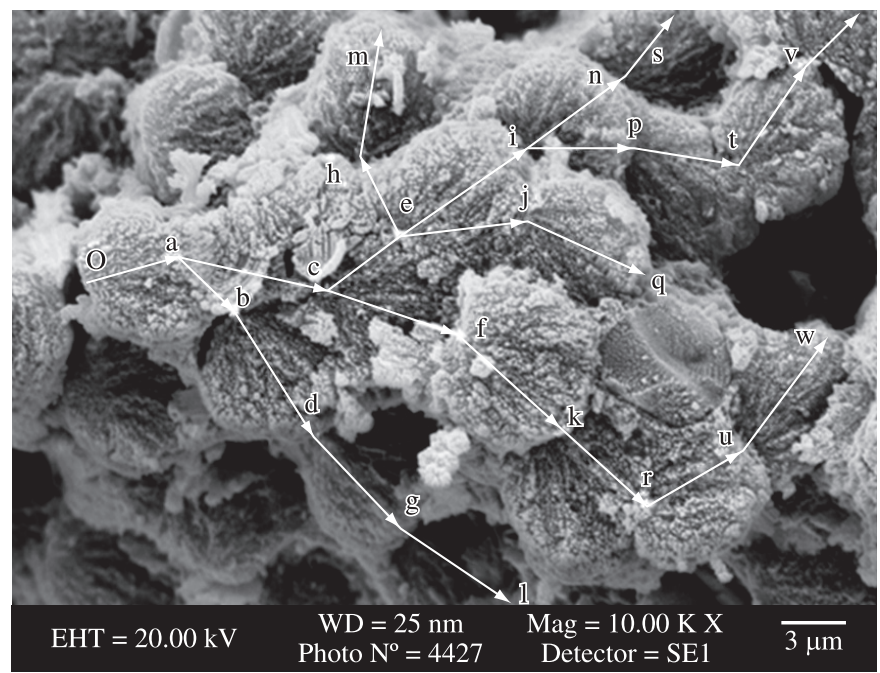

(f)

Figure 5. a) SEM fractograph of brittle failure showing radial lines from origin; b) Fiber pull-out from the matrix presenting holes on the fracture surface; c) Radial Marks on the Fiber Fracture Surface at High Magnification; d) Initiation of radial marks \& propagation direction on fiber fracture surface; e) Fiber radials indicate the crack propagation direction (Arrows denoting local crack propagation direction); and f) SEM fractograph referring to the local crack propagation on individual fiber. 
Crack

origin

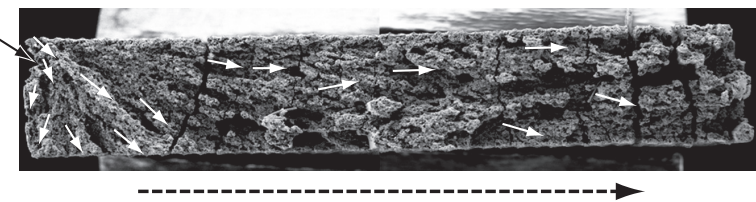

Figure 6. Map of overall crack propagation direction (White arrows indicate local crack propagation direction and the dotted arrow indicate overall crack propagation direction)

was determined by examining the cumulative crack direction of the individual fibers ${ }^{1}$. Also, the fiber radials and DAFF determines the direction of crack propagation and confirm the occurrence of the chevron effect. The fractographic features in the final fracture region were quite different from the crack propagation region and exhibited extensive longitudinal splits due to the local fracture in these regions prior to the arrival of the main crack front ${ }^{1}$. More number of secondary cracks is predominantly observed at final fracture zone.

\subsubsection{Fractographic characteristics of UD axial compression tested CFRP composite}

The macroscopic appearance (Figure 7) of the fracture surface was relatively smooth and it was oriented at an angle of $30-45^{\circ}$ to loading direction. SEM examination of the fracture surface revealed stepped structure at different locations as shown in Figures 8a and b. It has been observed that the micro-buckling/kinking which is the formation of reoriented material bands on a plane at some angle to the direction of loading ${ }^{21,22}$, occurs on several planes and the overall fracture surface sometimes consists entirely of series of steps, the height of each step being a multiple of half the buckling wavelength. Local fiber buckling/kinking and fiber fractures leads to an irregular, stepped fracture surface ${ }^{23}$. This is a characteristic feature of compression failure, i.e. failure of the fibers by micro-buckling/ fiber kinking (Figure 8c).

In Figure 8d, a typical compressive failure feature - Chop marks is observed ${ }^{1,17,23,24}$. High values of fiber volume ratio, shear or in phase mode micro-buckling has been predicted ${ }^{22}$, wherein the flexural stresses because of the in phase buckling leads to the formation of fracture planes (Figure 8c). At high magnifications in Figure 8e, the fracture surface of the individual fibers showed two distinct areas of smooth compressive and rough tensile areas separated by neutral axis (NA), known as chop marks, where its showing clear evidence of compressive failure from Compression side (C) to the NA and a tension failure from Tension side (T) propagating to the NA. It may also be noted; a strong bond between fiber and matrix is present in Figure $8 \mathrm{e}$ and also. The matrix and fiber debris were observed ${ }^{25,26}$, which is a characteristic of compression failed samples. Most of the fracture surface features were obliterated due to abrasion of mating fracture surfaces during failure, i.e. post-failure movement of the mating surfaces has caused abrasion over most of the fracture. And in Figure 8f, clearly neutral axis (buckling axis) can be observed and the local crack propagation direction is in the direction perpendicular to it. And the crack propagation is through the thickness. The crack propagates to fracture, through the individual fibers from the tensile to the compressive side in a direction perpendicular to neutral axis/ buckling axis (A-A). The fracture direction and height common to all the fibers in a step, indicate localized crack propagation. Thus, the buckling axis (Figure 8f) can be used for determination of the local crack propagation direction and hence identification of the failure origin. Also, a model explaining the damage zone leading to kink band formation/buckling has been researched ${ }^{27}$ in detail.

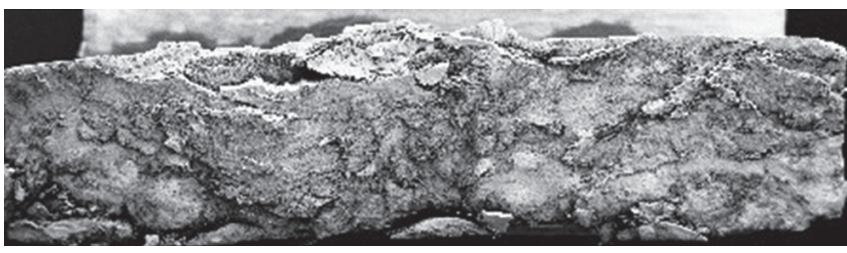

Figure 7. Cross-sectional view at the fracture surface of compression failed test coupon

\subsubsection{Fractographic characteristics of flexure tested CFRP composite}

Consider failures generated by the three-point bending (flexure loading), where in failure occurs at the central roller. A typical flexure failed composite fracture surface, as seen in SEM at least magnification is shown in Figure 9. A clear demarcation of tension and compression regions can be observed. The fracture surface had two morphologically different areas; rough area (tensile fracture) separated by distinct boundary with smooth area (compressive fracture), the boundary between them being parallel and often is close to the neutral axis (NA) of the laminate. The flexural failure has originated on the compression surface due to lower strength of CFRP in compression relative to tension and the stress concentration generated by the central roller. The crack then moves towards the NA, but since, as in the case of applied compression, the fractured surfaces are capable of sustaining substantial loads, the position of the NA may not move significantly. As the crack approaches the NA, it moves into a field of decreasing compressive stress and increasing inter-laminar shear stress, which stops the compressive fracture. And increased tensile strain (delamination) $)^{28,29}$ in the opposite face initiates rapid failure towards NA.

Examination of the rough area of the fracture surface revealed fiber pullout (Figure 10a) and the individual fibers showed radial marks (Figure 10c), which are similar to those observed in tension failed samples. The smooth area indicated micro-buckling, chop marks (Figure 10d) and compression debris (Figure 10b) similar to those observed in compression failed samples. Hence, flexural failures can normally be interpreted as a combination of tension and compression. Also, the local crack propagation direction is marked with red arrows in both Figure 10c and d.

The relative areas of the tensile and compressive regions would provide valuable information regarding the initiation of failure. For the samples under study, compression crack was considerably larger especially at free edges and propagated over an area of $70 \%$ of the fracture surface (Figure 9). This indicates compression crack initiated earlier than tension. This was due to low compression strength of CFRP than tensile strength and the stress concentration produced by central roller ${ }^{30}$. Also, the increased flexural strain allowed by the compression failure and the ability of these failed surfaces to react to significant loads cause a tensile failure to propagate from the opposite surface to meet the arrested compression failure. If crack initiates from the tension side, most of the fracture will be tensile in nature, since neutral axis will rapidly move away from the tensile surface as the crack propagates. The direction of crack propagation through the tensile fracture area determined from the radial marks on the fractures of individual fibers which indicate that the crack started from the external tensile surface and propagated into the specimen. 


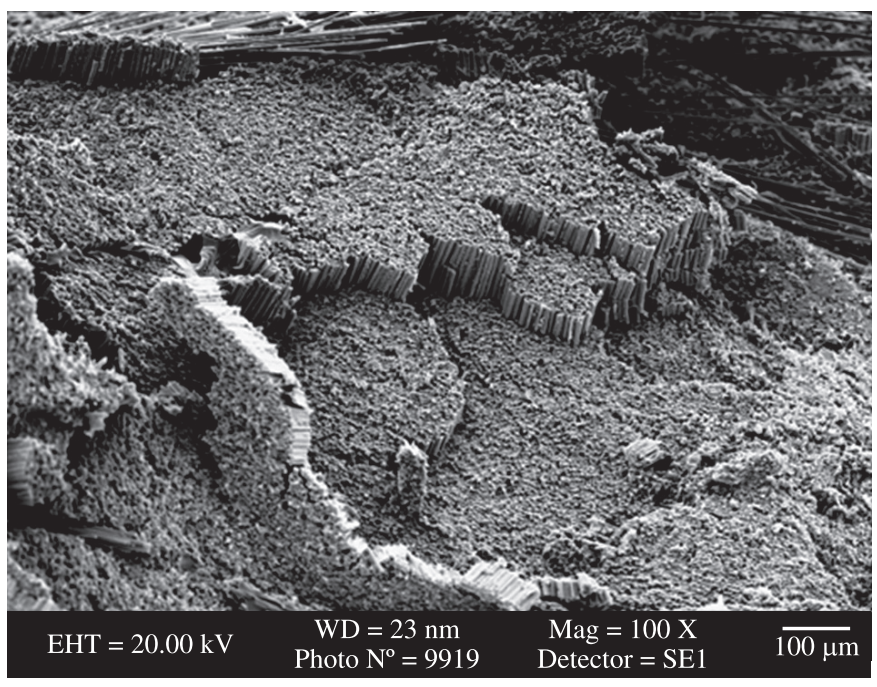

(a)

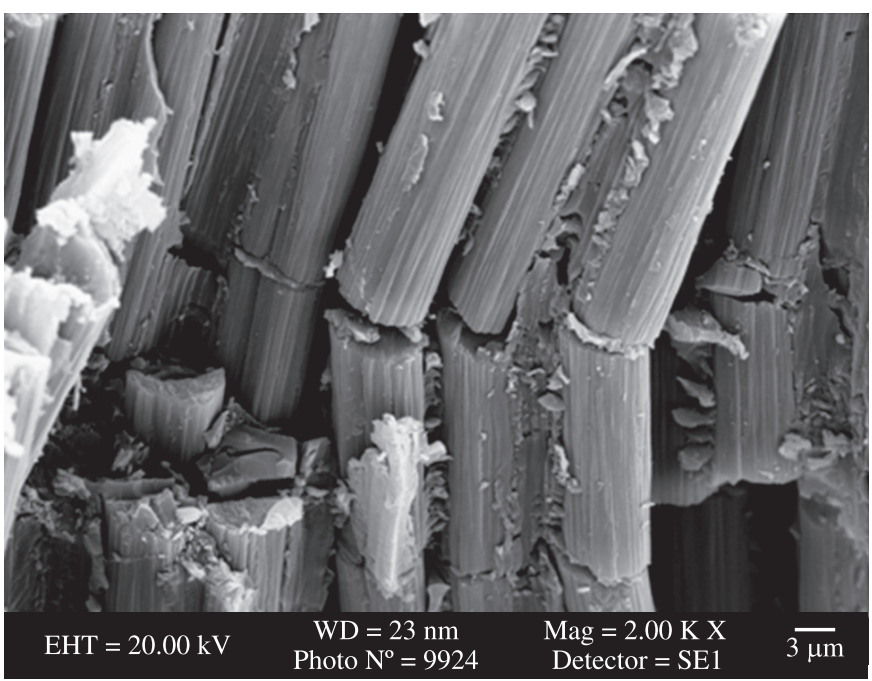

(c)

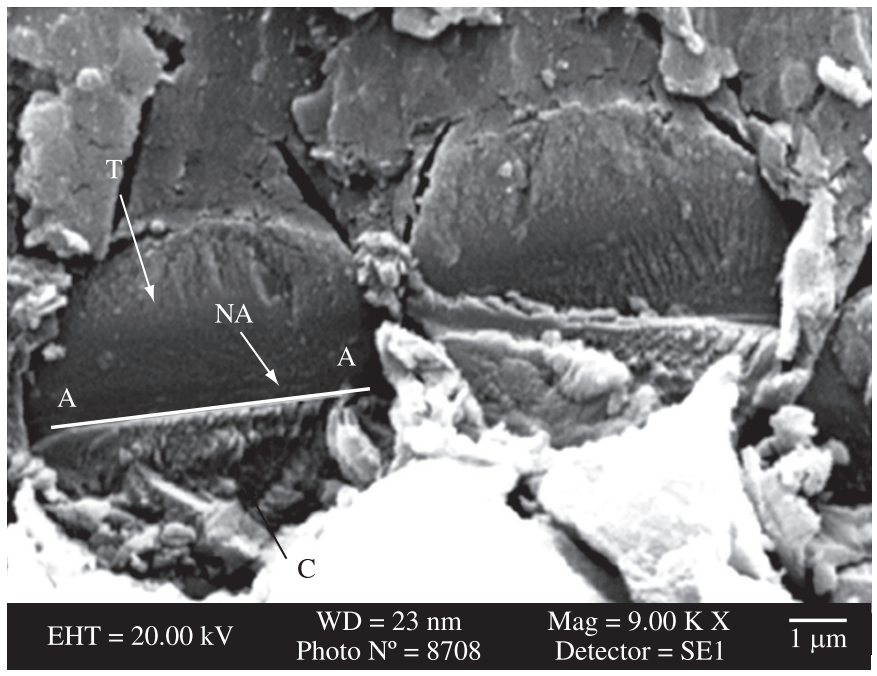

(e)

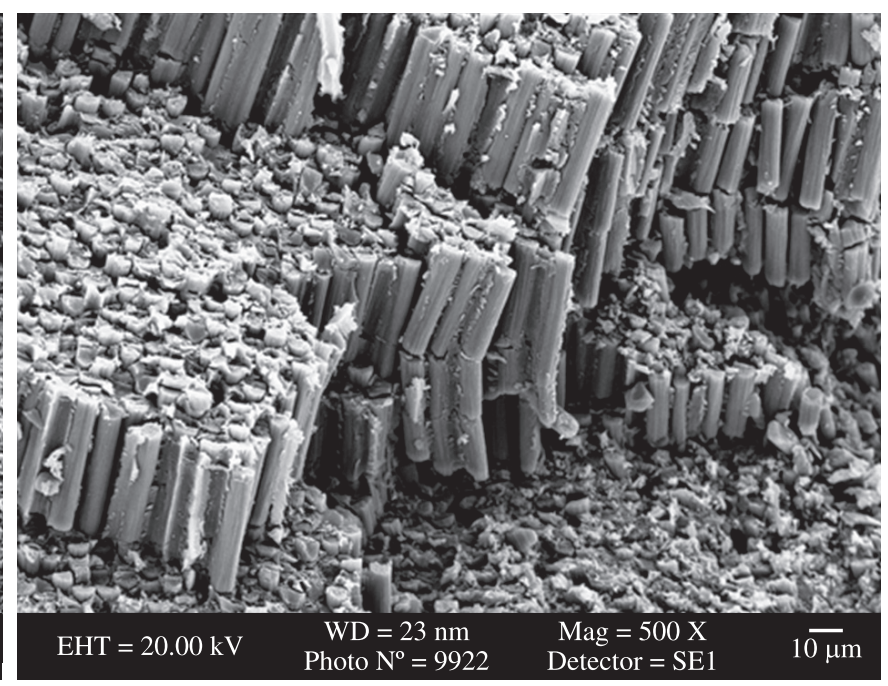

(b)

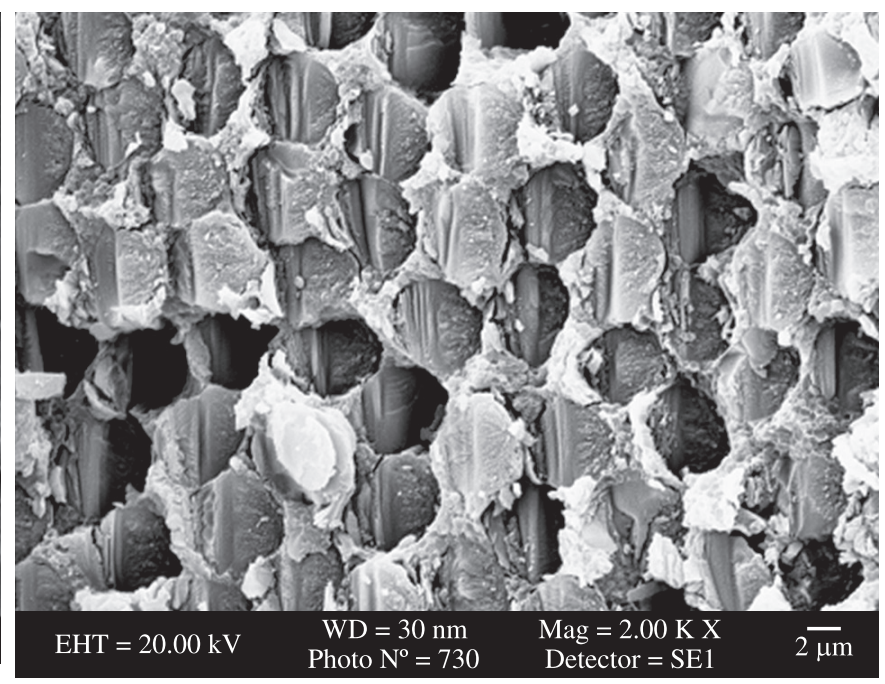

(d)

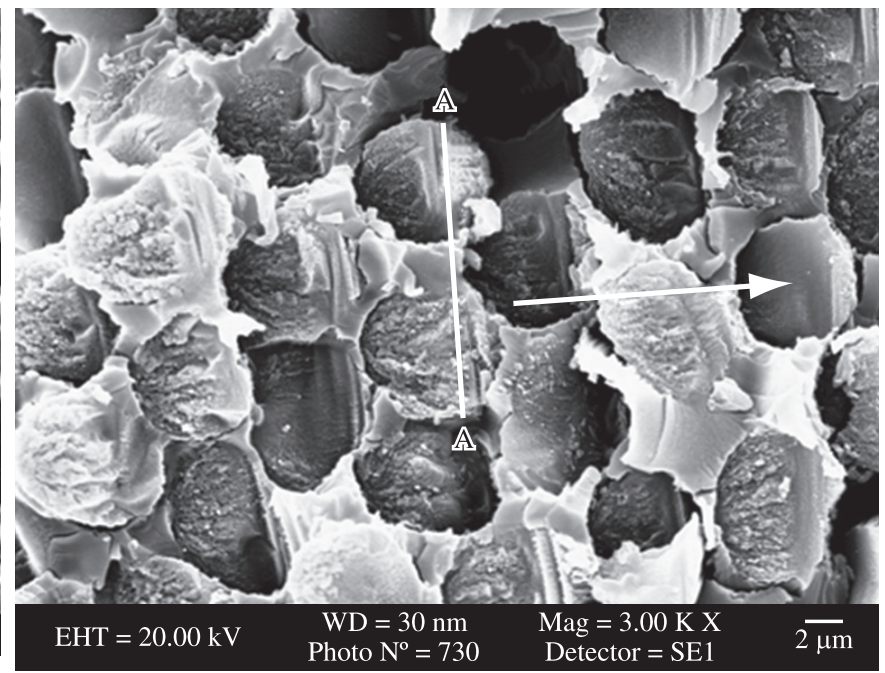

(f)

Figure 8. a) Stepped fiber fracture; b) Fiber fracture by micro buckling and fracture at different heights; c) Microbuckling/Kinking; d) Chop marks typical of failure under compressive load; e) High magnification fractograph showing chop marks separating tension and compression by neutral axis; and f) Local crack propagation direction indicated by an arrow perpendicular to neutral axis AA. 


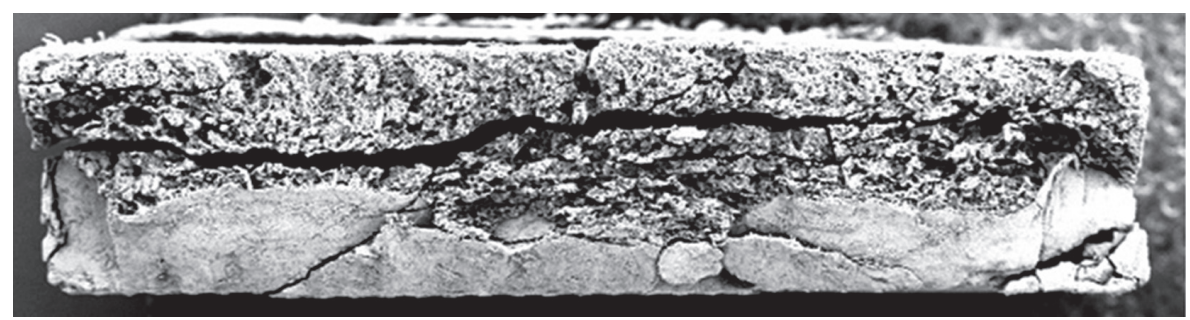

Figure 9. Flexure failed surface at least magnification. The clear demarcation of tension and compression regions can be observed.

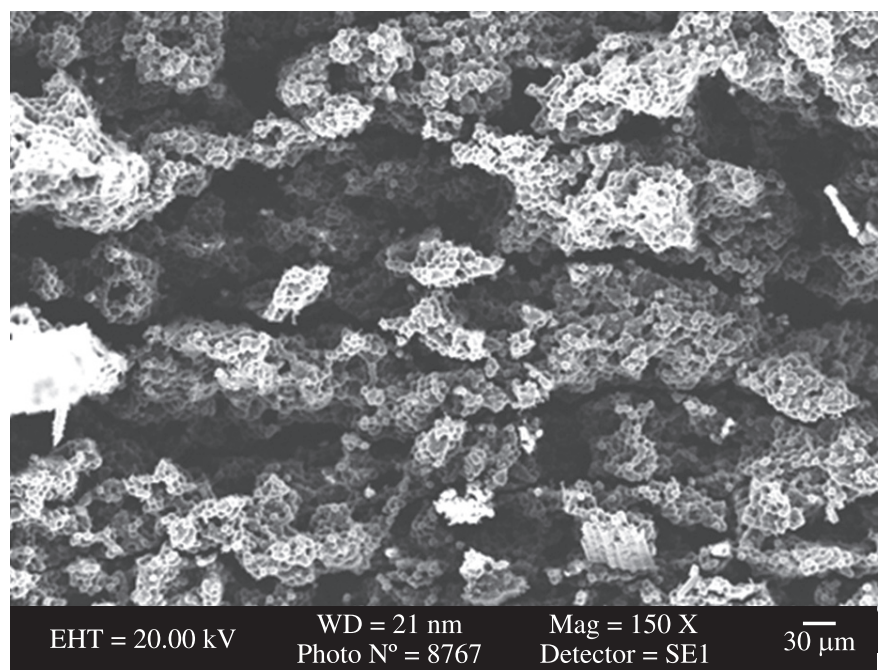

(a)

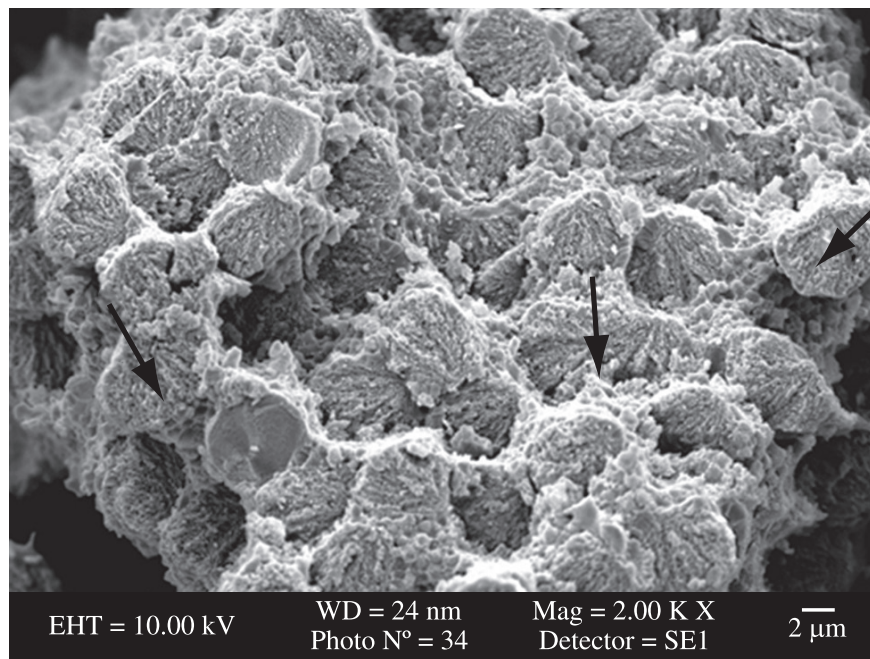

(c)

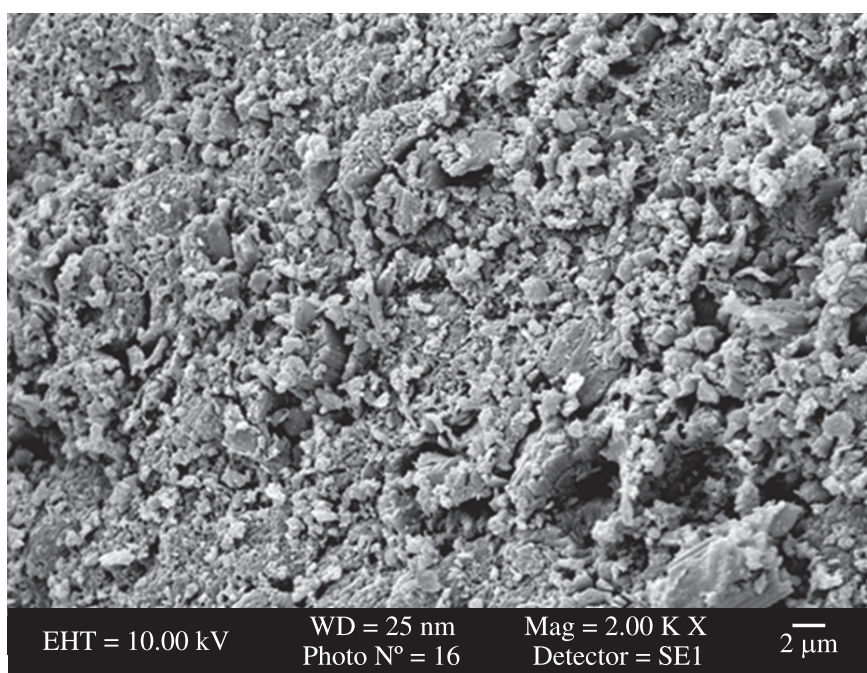

(b)

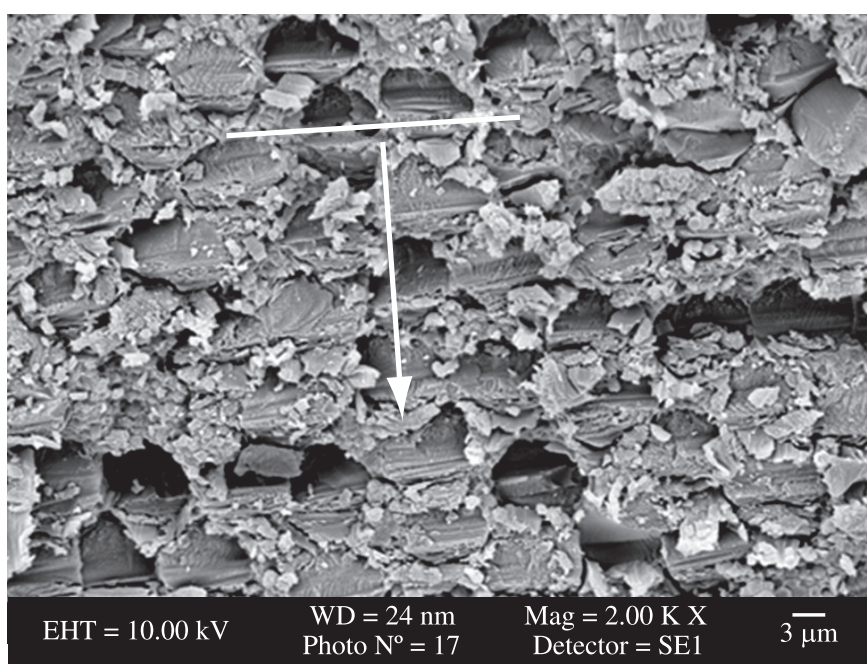

(d)

Figure 10. a) Fiber pullout on tensile side; b) Crushed and rub surface on compression side; c) Fiber radials on tension fractured fiber ends at higher magnifications; and d) Chop marks on compression side can be observed at higher magnifications.

\section{Conclusions}

Tension

- The axial tension failed samples exhibited macro-fractographic features such as rough surface, chevron lines, three distinct regions viz., crack origin, propagation and final failure and micro-fractographic features such radial marks on the individual fiber fracture ends.
- Using the DAFF method, it is possible to trace the path of fracture over significant areas of failure and by sampling a number of such areas, overall direction of tensile failure in a composite can be determined. Also, following the root system of sequential failures (DAFF method) back towards the origin, it becomes evident that a whole group of failures may be traced back to the fracture of one fiber. 


\section{Compression}

- The predominant macroscopic failure mode in the axial compression failed samples has been identified as shear crippling (the result of kink-band formation resembling the slip lines in metals) which leads to shear failure on a plane at an angle of $30-45^{\circ}$ to the direction of loading.

- The micro-fractographic informed that the micro-buckling occurs on several planes and the overall fracture surface consists of a series of steps and the buckling axes separate compressive failures (C) from tensile failures $(\mathrm{T})$ on the individual fibers.

\section{Flexure}

- The flexure failed samples showed features such as distinct tensile and compressive fracture areas (compression-tension boundary). The delamination and failure cause the neutral axis to move towards the tensile surface and failure recommences as a compression fracture. Therefore, the relative areas of the tensile and compressive regions would provide valuable information regarding the initiation of failure.

Therefore, this research has led to the knowledge of the nature and origin of fracture, as well as understanding of how the fracture occurs, with an insight into the various characteristic features and its effect of these on the failure modes with the definition of overall crack propagation direction. All these characteristics are very valuable in the aerospace structures fabricated by CFRP. The characteristics described here may be applied to other fibers (such as Glass, Kevlar, Boron etc.,) and matrices to form a sound basis for further research into composite materials under varied environmental conditions (moisture and temperature) and other loadings such as fatigue, impact etc., However, composites fractography is proving to be powerful and reliable tool for the composite engineer, and is a vital technique for the overall development and design of composite structures.

\section{References}

1. Purslow D. Some fundamental aspects of composites fractography. Composites. 1981; 12(4):241-247.

2. Viviane G, Barcia FL and Soares BG. Composite Materials based on Modified Epoxy Resin and Carbon Fiber. Journal of Brazilian Chemical Society. 2006; 17(6):1117-1123.

3. Fortsch W, Franz HE and Friedrich K. Micro-fractographic Aspects of Interfaces in CFRP under Fatigue Loading. In: Proceedings of the 28th Riso International Symposium on Materials Science; 2007; Denmark.

4. Marinucci G and Arnaldo HPA. Micro-structural Analysis in Asymmetric \& Unbalanced Composite Cylinders Damaged by Internal Pressure. Composite Structures. 2006; 72:86-90.

5. Purslow D. Fractographic analysis of failures in CFRP, In: Characterization, Analysis and Significance of Defects in Composite Materials (AGARD CP 355). 1983.

6. Kim P. A comparative study of mechanical performance and cost of Metal, FRP and Hybrid beams. Applied Composite Materials. 1998; 5:175-187.

7. Toshiyuki S, Yoshiaki K, Yasumasa $\mathrm{H}$ and Takenori A. Static and Fatigue Strengths of a G40-800/5260 Carbon Fiber/Bismaleimide Composite Material at Room Temperature and $150^{\circ} \mathrm{C}$. Journal of Composite Materials. 2008; 42:655-679.

8. Greszczuk KB. Fracture of Composite Materials. In: Sih GC and Tamuzs VP, editors. Proceedings of Second USA-USSR Symposium on the Fracture of Composite Materials; 1981; Pennsylvania, USA. p. 231-244.
9. Johannesson T, Sjoblom P and Selden, R. The detailed structure of delamination fracture surfaces in graphite/epoxy laminates. Journal of Material Science. 1984; 19(4):1171-1177.

10. Liechti KM, Masters JE, Ulman DA and Lehman MW. Technical Report AFWAL-TR-82-4035. Texas: General Dynamics/Fort Worth Division; 1982.

11. Miller AG and Wingert AL. ASTM STP 696. Philadelphia: ASTM; 1979.

12. Purslow D. Matrix fractography of fiber reinforced epoxy composites. Composites. 1986; 17(4):289-303.

13. Lynch SP and Moutsos S. A brief history of fractography. Journal of Failure Analysis and Prevention. 2006; 6(6):54-69.

14. Parrington RJ. Fractography of Metals and Plastics. Journal of Failure Analysis and Prevention. 2002; 2(5):16-19.

15. Fractography. In: ASM Handbook. USA: ASM International; 2002. vol. 12.

16. Sapalidis $S$, Hogg P and Youd S. High temperature acidic stress corrosion of glass fibre composites: Part I - Effect of fibre type. Journal of Materials Science. 1997; 32(2):309-316.

17. Greenhalgh ES and Hiley MJ. Fractography of Polymer Composites: Current Status and Future Issues. In: Asp L and Gamstadt K, editors. 13th European Conference on Composite Materials; 2008; Stockholm, Sweden.

18. Purslow D. Fractography of Fiber-Reinforced Thermoplastics, Part 3. Tensile, Compressive and Flexural Failures. Composites. 1998; 19(5):358-366.

19. Jaminson RD. ASTM STP 907. Philadelphia: ASTM; 1986.

20. Hull D. Fractography: Observing, Measuring, and Interpreting fracture surface topography. Cambridge University Press; 1999.

21. Hahn HT. In: Matthews FL, Buskell NCR, Hodgkinson JM and Moston J., editors. Proceedings of the 6th International Conference on Composite Materials; 1987; London: Elsevier Applied Science; 1987. p. 269.

22. Parry TV and Wronski AS. Kinking and compressive failure in uniaxially aligned carbon fibre composite tested under superposed hydrostatic pressure. Journal of Material Science. 1982; 17(3):893-900.

23. Shikhmanter L, Eldor I and Cina B. Fractography of Unidirectional CFRP Composites. Journal of Materials Science. 1989; 24(1):167-172.

24. Rosen BW. Mechanics of Composite Strengthening. In: Fiber Composite Materials. Ohio: ASM; 1965. chap. 3.

25. Garland BD, Beyerlein IJ and Schadlera LS. The development of compression damage zones in fibrous composites. Composites Science Technology. 2001; 61:2461-2480.

26. Budiansky B and Fleck NA. Compressive failure of fibre composites. Journal of the Mechanical Physics of Solids. 1993; 41:183-211.

27. Vinod MS, Sunil BJ, Vinay N, Raghavendra S, Murali MS and Nafidi A. Fractography of compression failed carbon fiber reinforced plastic composite laminates. Journal of Mechanical Engineering Research. 2010; 2(1):1-9.

28. Kozey VV. Fibre strength-dominated failure mode in unidirectional composites under compression. Journal of Materials Science Letters. 1993; 12(1):48-52.

29. Greenhalgh ES, Rogers C and Robinson P. Fractographic observations on delamination growth and the subsequent migration mechanisms through the laminate. Composites Science and Technology. 2009; 69(14):2345-2351.

30. Coban O, Mustafa OB, Tamer S, Ismail C and Volkan G. Fracture morphology and deformation characteristics of repeatedly impacted thermoplastic matrix composites. Materials and Design. 2009; 30:628-634. 